\title{
A crisis of authority in scientific discourse
}

\author{
Marcia D. Nichols ${ }^{1}$ (D) . Andrew M. Petzold ${ }^{1}$ (i)
}

Received: 12 February 2020 / Accepted: 21 June 2020 / Published online: 9 January 2021

(c) Springer Nature B.V. 2021

\begin{abstract}
Scientific training often begins with learning content knowledge and techniques. As a student progresses, they are required to communicate the results of their experiments with their instructors in a manner that other scientists would understand. This style of communication is stressed throughout their entire training. But what happens when the need arises to communicate with interested nonscientific audiences? Scientific discourse has typically been considered what philosopher of language Mikhail Bakhtin termed an "authoritative discourse,"- a discourse that "binds us, quite independent of any power it might have to persuade us internally," whose hegemony is traditionally a priori, unquestioned. However, within the public realm, that authority is in crisis. There is an unsettling rise of anti-scientific counter-discourses such as the anti-vaccine movement, the growing Flat Earth movement, climate change denialism, and a host of other "movements" grounded in either pseudo-science or an outright dismissal of scientific authority. In response to this crisis, scientists and educators have called for more attention to improving scientific literacy among the general public. By examining the generic conventions of scientific discourse using the theories of Mikhail Bakhtin, we hope to point out some of the barriers causing the current crisis in scientific authority.
\end{abstract}

Keywords Scientific discourse $\cdot$ Authoritative discourse $\cdot$ Bakhtin $\cdot$ Science communication $\cdot$ Scientific authority

Scientific training often begins with learning content knowledge and techniques. As a student progresses, they are required to communicate the results of their experiments with their instructors in a manner that other scientists would understand. This style of communication is stressed throughout their entire training. As has become obvious in the American response to the current global pandemic, scientific training should include instruction on how to communicate with interested nonscientific audiences. However, in the experience of one of the authors, it hasn't. During his training, he learned that many of his peers felt the best way to interact with non-scientists was to begin with complex information, slowly becoming less complex until they recognized that their audience was feigning understanding or losing interest. It seemed that among his scientific peers, there were two camps:

Marcia D. Nichols

mdnichol@r.umn.edu

1 Center for Learning Innovation, University of Minnesota, Rochester, Rochester, MN 55904, USA 
those who were interested in altering their style of communication to fit their audience and those who hoped the audience would alter their understanding to meet the speaker. This dichotomy seems to be shifted heavily toward those who focus on peer-to-peer communication over communication to others so much so that it has become a major plot point in a number of pop culture items (see The Big Bang Theory). Within the field of science communication, this is referred to as information deficit model (Dickson 2005).

Scientific discourse has typically been considered what philosopher of language Mikhail Bakhtin, Holquist and Emerson (1981, p. 343) termed an "authoritative discourse,"a discourse that "binds us, quite independent of any power it might have to persuade us internally," whose hegemony is traditionally a priori, unquestioned. However, within the public realm, that authority is in crisis. There is an unsettling rise of anti-scientific counterdiscourses such as the anti-vaccine movement, the growing Flat Earth movement, climate change denialism, and a host of other "movements" grounded in either pseudo-science or an outright dismissal of scientific authority. Most recently, we've seen this anti-science backlash during the COVID-19 global pandemic in the rush to reopen businesses, the refusal to wear masks, and the rise of a variety of conspiracy theories and fringe treatments that endanger everyone. In response to this crisis, scientists and educators have called for more attention to improving scientific literacy among the general public. While this is a necessary endeavor, we want to suggest, as others have before, that science communication itself could be improved. By examining the generic conventions of scientific discourse using the theories of Bakhtin, we hope to point out some of the barriers causing the current crisis in scientific authority.

Bakhtin et al. (1981, p. 344) characterizes authoritative discourse as "hard-edged, a thing in its own right" characterized by "semantic finiteness and calcification"-in other words, as centripetal and monologic as opposed to centrifugal, heteroglossic novelistic discourse. In fact, the generic convention of monologic scientific discourse presents itself as authorless; however, any utterance, including a scientific utterance is geared toward an audience who will imaginatively embody an author. Greater attention to the inflections and context that potential audiences might bring to scientific discourse could improve communication. Moreover, the generic conventions of academic science make it necessarily heteroglossic. Writers of scientific discourse are expected to enter into a dialogue with their peers and the work that has already been done upon a given research question. Although scientific discourse, as it seeks to answer these research questions, moves centripetally toward a monologic authoritative discourse, the competition and variety inherent in Western academia function as centrifugal forces that fret the edges of authority. Additionally, Bakhtin's theory of speech genres and the socio-ideological nature of professional languages and styles complements the work of feminist theorists such as Evelyn Fox Keller, Anne Fausto-Sterling, and others, which has argued that Western scientific discourse tends to ignore or silence marginalized voices and contributors (Fox Keller and Longino 1996). By examining scientific discourse through a Bakhtinian lens, we will demonstrate some of the factors contributing to this crisis in scientific authority and propose that greater attention to audience, to imbedded ideology, and the recognition of the heteroglossic nature of academic scientific discourse point toward avenues for addressing this crisis.

Scientific discourse attempts to present knowledge in an objective, neutral, biasfree manner. However, according to Bakhtin et al. (1981, p. 293), "there are no "neutral' words and forms-words and forms that can belong to 'no one'; language has been completely taken over, shot through with intentions and accents." If language is never a neutral medium, then scientific discourse can also never be neutral, never truly be objective. Nevertheless, scientific discourse attempts to construct an objective stance through 
the particular stratification of its language and its generic conventions. In particular, this occurs through a standard organizational structure (IMRaD), the frequency of nominalizations, and the use of passive voice.

Most scientific research articles are organized in a fairly rigid structure: Introduction, Methods, Results, and Discussion-often shortened to IMRaD (International Committee of Medical Journal Editors 2019). This structure was adopted during the 1920s and was suggested as the ideal method of writing papers but didn't become prevalent until the 1930-1940s (Wulster-Radcliffe, Hamernik, Reynolds, Lewis, and Zinn 2005). "Development and changes in the internal organization of the scientific article is simply an answer to the constant growth of information. The IMRaD structure facilitates modular reading, because readers usually do not read in a linear way but browse in each section of the article, looking for specific information, which is normally found in pre-established areas of the paper" (Meadows 1985).

While it may have been adopted for the ease of modular reading, for much of scientific discourse IMRaD has become a "relatively stable type[] of utterance[]"-in other words, a complex "speech genre" (Bakhtin, Vern, Emerson, and Holquist 1986, p. 60), with a "stylistic aura" that encompasses both typical "themes" and "meanings" (Bakhtin 1986, p. 87). On the one hand, the ascendancy of IMRaD is an example of the way that relatively stable utterances coalesce into speech genres. On the other, it is possible to see this rigid structure is a centripetal attempt of authoritative discourse to stratify and control language's inherent heteroglossia: "It is in fact not the neutral linguistic components of language being stratified and differentiated, but rather a situation in which the intentional possibilities of language are being expropriated...they knit together with specific objects and with the belief systems of certain genres of expression and points of view peculiar to particular professions" (Bakhtin et al. 1981, p. 289). In Bakhtinian terms, the IMRaD structure encapsulates the worldview and belief systems of scientific discourse. In other words, generic style is "a form of politics" (Clark and Holquist 1984, p. 210). It behooves us to dissect this standard structure to get at the unspoken socio-ideological beliefs that make the IMRaD structure synonymous with "science."

In some ways, the repeatability of the IMRaD structure mimics the repeatability that scientific experiment attempts to achieve. As Gary Morson and Caryl Emerson (1990, p. 117) explain, "Bakhtin concedes that monologiziation and transcription have their legitimate uses. In the hard sciences, for instance, a researcher's interest may lie precisely in what is repeatable and stateable as monologic propositions." Scientific results are most valid when they are repeatable. Having a genre that also is repeatable offers rhetorical support for the validity of scientific discourse. Indeed, perhaps the IMRaD genre itself has become the format of scientific fact-that something seems more "true" or "valid" when it is presented in this structure than otherwise. This could, and likely has, led to invalidating other ways of knowing. For instance, Western science has been criticized for ignoring indigenous knowledge and ways of knowing, resulting in the "discovery" of flora and fauna long identified and understood by indigenous peoples (Agrawal 1995). Feminist scholars have also critiqued scientific discourse for having an androcentric bias that colors and distorts not only the problems asked, but also how experiments and designed and conducted and how results are interpreted (Fox Keller and Longino 1996).

Without delving into the masculinist bias of logocentrism, it seems likely that form influences matter as much as matter influences form. If IMRaD was developed and perpetuated for its ease of modular reading, which mimics the controlled and modular steps of an experiment, then could outliers in information, in insight, in ways of knowing, in uncertainty be left out of scientific discourse much as they are often left out of statistical 
analyses? How might those lacunae impede communication between the scientific community and the larger population?

Knowledge, and the communication of knowledge, tends to be messy. It's not rigidly organized or modular as a scientific worldview seeks to present it. Rather, knowledge is often narrative, anecdotal, reasoned from a particulari ad universale, which is in stark contrast to scientific discourse that uses IMRaD format as the carefully organized presentation of a deductive experiment. If for scientists, "fact" or "truth" comes packaged in IMRaD, for a "lay" audience, "fact" or "truth" comes packaged as story based on individual, empirical evidence. Thus, miscommunication seems almost inevitable in a situation when both groups of interlocutors lack training in understanding the communication norms of each other.

But structure is only the tip of the iceberg of miscommunication. Two grammatical aspects of the style of scientific discourse-scientific nominalizations and the frequent use of passive voice-also set the stage for lack of understanding between the scientific world and the larger population.

One aspect of scientific language that can feel especially "foreign" for the non-scientist is the "frequency of grammatical metaphor, from the union of nominalization with recursive modification of the nominal group" (Haliday and Martin 2003, p. 15). What in "reality" and in everyday language is both things (nouns) and processes (verbs), scientific discourse tends to nominalize in order to "holds reality still, to be kept under observation and experimented with; and in so doing, interprets it not as changing with time (as the grammar of clauses interprets it) but as persisting-or rather, persistence-through time, which is the mode of being a noun" (Haliday and Martin 2003, p. 15). The verb-the action-in scientific discourse tends to be objectified-"that is, representing actions and events, and also qualities, as if they were objects. As a corollary to this, the relations between events came to be construed as if they were the events themselves" (Haliday and Martin 2003, p. 52). In other words, in order to theorize about phenomena, scientists hold them still in the form of nouns. At the same time, this results in nominal clause building upon nominal clause, barnacle-like, upon passive verbs, creating a lexically dense web of things seemingly observed by a non-grammatically present scientist. For the non-specialist, navigating this nominalized terrain can be quite daunting for a variety of reasons. Lexically, just unweaving the dense web of signifiers can be difficult, even for academics. Moreover, the level of abstract thought that nominalizes actions into things requires not only training, but also a worldview or epistemology that can be at real odds with that of an "average" person.

Passive voice is a necessary consequence of the nominalizing trend in scientific discourse. Actions are turned into events, into nouns, connected together by polysemous passive verbs, like "to be," in an ontological stasis. This might metaphorically pin down phenomena in order to study and theorize it, but it also creates convoluted writing that often hides not only the action, but the actor. Ideologically, hiding of the actor-the scientistsis an attempt to discursively capture the goal of scientific objectivity-it places the scientists as observers of phenomena and experiments. However, passive voice hides their roles, not only as interpreters of data, but as designers and manipulators of the scientific occasion that is being reported. To a general population, then, passive voice can seem disingenuous, akin to a politician's use of passive voice to "pass the buck."

To illustrate these points, we will dissect two sentences taken at random from recent scientific publications, the first from biology and the second from computer science.

"Using video recordings, response threshold evaluation, sleep disturbance experiments, and detailed behavioral analyses, I we established I that the sleep-like state 
of bumble bee (Bombus terrestris) workers shows the essential behavioral and physiological characteristics of sleep and is particularly similar to that of the honeybee"

(Nagari, Gera, Jonsson and Bloch 2019)

"In programming language semantics, I normalization by evaluation (NBE) is a technique I of computing the output of a program $\mathrm{P}$ by appealing only to the denotational semantics of P" (Chouquet, Guerrieri, Pellissier and Vaux 2017)

In the first sentence, the independent clause (between I), "we established" is in active voice; however, "establish" is relatively abstract, polysemous transitive verb. It is not a clear or concrete action. This main clause is modified by an opening participle phrase and a restrictive clause that functions as the direct object. To begin, the opening participle phrase nominalizes the entirety of the scientific observations and experiments-all of actions that it likely took "we" years to perform (recording, evaluating, experimenting, analyzing) — in a phrase that is not even grammatically necessary for the sentence. Moreover, the verb participle, "using," on which all these nominalizations hang is also an abstract, polysemous verb. The restrictive clause functioning as the direct object of "establish" contains all of the information about the subject of these nominalized scientific actions-the bumblebee worker. However, grammatically, the bee is the object of a preposition rather than the subject of the restrictive clause. The bee's ongoing actions have been nominalized-objectified as a "sleep-like state" - and the activities that occur during this "state" are presented as a further abstraction (characteristics) of an already abstract noun (character). The verbs in this restrictive clause (shows and is) are likewise abstract and polysemous. The entire restrictive clause is tautological-that a "sleep-like state" is in fact, like "sleep." In other words, unpacking this sentence would take a team of highly trained movers. Each of these nominalizations is in itself a Pandora's box of ideas and activities that "we" seem to hope readers possess the ability to parse.

In the second sentence, the stripped-down independent clause is "normalization... is a technique." Or in other words, a Latinate, nominalized, abstract concept is a Greco-Latin abstract concept. "Normalization" is a dead metaphor, originating in the Latin "norma" or right-angled. The nominalized form used here first came into use in nineteenth-century science to characterize the attempts to have concepts and phenomena conform to a ruleto "square" them (Oxford English dictionary 2014). In this case, however, the sentence modifies "normalization" with a prepositional phrase ("by evaluation"-itself another nominalization of a Latinate verb, based on the Latin stem -val-, meaning "worth"). Thus, one might unpack this independent clause ("normalization of evaluation is a technique") quite literally as "the act of squaring the state or condition of determining worth is skill set." Of course, the acronym ("NBE") tells us that "normalization of evaluation" is not just a vague normalization, but is a specific, concretized process known to those initiated into computer science language-e.g., "programming language semantics." This latter is also an esoteric phrase-what "programming language semantics" is really only understood by the initiated. Moreover, the "is" of the main clause tells us that this sentence is definitional - that the object ("technique" modified by prepositional phrases) will define the subject ("normalization" modified by prepositional phrases). In other words, it is supposed to initiate the un- or only partially initiated. To do so, "technique" is modified by a series of prepositional phrases. The first, "of computing the output," features a gerund phrase as the object of the preposition "of." In this instance, both the verbal (computing) and its direct object (the output) are abstractions. This gerund phrase is further modified by two additional prepositional phrases. The first "of a program P" is again an abstract noun. The second, ("by appealing...") is another gerund phrase. "Appealing" is the most 
concrete verbal in the entire sentence as it does conjure up a particular action. However, this gerund phrase is itself modified by a sixth prepositional phrase ("to the denotational semantics"). In this sixth prepositional phrase, "denotational" is the adjectival form of a nominalized verb (denote). "Semantics," which begins and ends this sentence, is a word ripe for miscommunication. In academia, for the initiated, "semantics" is a field of study that researches how a language or languages function. But for the lay population, "semantics" usually means straining at gnats-focusing on unimportant verbal differences rather than big picture similarities.

Perhaps this careful breakdown of what might be called recursivity run amok is itself straining at gnats. Both of these examples, after all, are taken from texts written by scientists for scientists. At the same time, however, their esoteric opacity could seem like a deliberate dis-invitation to potential lay readers interested in these topics. Bees, after all, are crucial for the survival of life as we know it on this planet, and Bombus terrestris's American cousin was placed on the Endangered Species List in 2019. It is not unreasonable to assume that there might be lay interest in the humble bumblebee. Moreover, while programming language is, in fact, another language, computer programming intimately impacts the lives of pretty much every person on the planet. Writing in a way that invites the curiosity of the general public would do much toward bridging the gulf between them and the scientific specialist.

In Bakhtinian terms, scientific discourse is an example of "a professional stratification of language" (1981, p. 289), which, on the one hand, in necessary for a field like science because such stratification allows for particular kinds of thought and inquiry. Creating a specialized language or means of communication can facilitate communication among a specialized group. Because language is often a key element to insider-outsider status and group formation, language stratification and specialization is perhaps a necessary and natural phenomenon in any socially stratified society. On the other hand, language stratification also limits what can be communicated about across groups. "Language is seen as both carrier and creator of a culture's epistemological codes. The ways we speak and write are held to influence our conceptual boundaries and to create areas of silence as language organizes meaning in terms of pre-established categories" (Lather 1991, p. 74). These areas of silence are ripe, not only for epistemological blind spots, but also as pitfalls for cross-group communication. As Bakhtin et al. (1981, p. 289) explains, "For such outsiders [to a stratified language], the intentions permeating these languages become things, limited in their meaning and expression."

Jay Lemke (1990, pp. 129-30) has argued that science teaching has alienated students from science because "the language of classroom science sets up a pervasive and false opposition between a world of objective, authoritative, impersonal, humourless scientific fact and the ordinary, personal world of human uncertainties, judgments, values, and interests." We think that this dilemma could easily be extended beyond the classroom to characterize the alienation so much of the general population seems to feel toward science and scientific discourse. Michael Halliday and James R. Martin suggest that part of this reaction is that the lexicogrammar of science can make one's native language is made to feel foreign to the uninitiated (2003, p. 4). While a specialized language is necessary for scientific endeavors, a better understanding of how everyday language is changed into a technical language could help scientists better communicate with the general population.

For the non-scientist, then, scientific language is "foreign," opaque, alienating, all of which can foster mistrust toward the scientific community, especially when the complexities of scientific discourse seem unnecessary or a deliberately erected barrier to communication. As Lemke (1990, p. 172) describes it "It is a foreign "register" ... ... within 
English, and it sounds foreign and uncomfortable to most." According to Halliday and Martin (2003, p. 21), "The language of science, though forward-looking in its origins, has become increasingly anti-democratic: its arcane grammatical metaphor sets apart those who understand it and shields them from those who do not." Charges of elitism, often aptly, are frequently hurled at the academy as a whole, not just at the scientific community, and all academics and scholars should consider how to more clearly communicate their crucial research and knowledge to a general population. For instance, how accessible is this paper, which is about communication barriers, to those without some knowledge of and training in language theory or philosophy? This dilemma is especially salient for the sciences, because of the various crises the world at large is facing. This has been driven home with the most recent global crisis, the novel coronavirus (SARS-CoV2), that has infected millions of people, caused hundreds of thousands of deaths in less than half a year, and that has wrought unknown havoc on local and global economic systems. While misunderstanding this paper might create ill-will or add to the anti-intellectualism marring too much of US society, misunderstanding or dismissing science has much more dire consequences. The current anti-science response to the global pandemic is just the latest anti-science discourse that is posing an existential threat. It joins previous backlashes such as the anti-vaccine movement that has resulted in the reemergence of measles as a serious health threat and climate change denialism that has endangered life as we know it on this planet. It is easy to blame these crises solely on the lack of scientific literacy among the general public. Perhaps, however, the scientific community — and academia at large — should remember the lesson in Sophocles' Oedipus Rex of looking to oneself for the flaw destroying the kingdom. If scientific discourse is to remain an authoritative one, it needs to practice some outreach by being less esoteric, less monologic. In other words, scientific discourse needs to be more willing to recognize the messiness of the conditions outside the laboratory and more willing to listen to and incorporate the heteroglossic voices and knowledge of the lay population as it seeks to disseminate its vital findings to a world in crisis.

\section{References}

Agrawal, A. (1995). Dismantling the divide between indigenous and scientific knowledge. Development and Change, 26, 413-439.

Bakhtin, M., Vern, W. M., Emerson, C., \& Holquist, M. (1986). Speech genres and other late essays. Austin, TX: University of Texas.

Bakhtin, M., Holquist, M., \& Emerson C. (1981). The dialogic imagination. four essays by M. M. Bakhtin. Austin, TX: University of Texas.

Dickson, D. (2005). The case for a 'deficit model' of science communication. SciDevNet. https://www.scide v.net/global/communication/editorials/the-case-for-a-deficit-model-of-science-communic.html.

Chouquet, J., Guerrieri, G., Pellissier, L., \& Vaux, L. (2017). Normalization by evaluation in linear logic. In Preproceedings of the international workshop on trends in linear logic and applications, TLLA. https ://www.i2m.univ-amu.fr/perso/lionel.vaux/pub/nbell-tlla.pdf.

Clark, K., \& Holquist, M. (1984). Mikhail Bakhtin. Cambridge, MA: Harvard University.

Halliday, M. A., \& Martin, J. R. (2003). Writing science: Literacy and discursive power. London: Routledge. https://doi.org/10.4324/9780203209936.

International Committee of Medical Journal Editors. (2019, October 26). Recommendations for the conduct, reporting, editing, and publication of scholarly work in medical journals. Retrieved from: https://www. icmje.org/recommendations/.

Keller, E. F., \& Longino, H. E. (1996). Feminism and science. Oxford: Oxford University Press. 
Lather, P. (1991). Getting smart: Feminist research and pedagogy within/in the postmodern. London: Routledge.

Lemke, J. L. (1990). Talking science: Language, learning, and values. New York: Ablex Publishing Corporation. https://doi.org/10.4324/9780203451311.

Meadows, A. J. (1985). The scientific paper as an archaeological artifact. Journal of Information Science, 11, 27-30. https://doi.org/10.1177/016555158501100104.

Morson, G. S., \& Emerson, C. (1990). Mikhail Bakhtin: Creation of a prosaics. Stanford, CA: Stanford University Press.

Nagari, M., Gera, A., Jonsson, S., \& Bloch, G. (2019). Bumble bee workers give up sleep to care for offspring that are not their own. Current Biology, 29(20), 3488-3493.

Oxford English dictionary. (2014). Normalization. In Oxford English dictionary. Oxford University Press. Retrieved from: https:/www.oed.com/view/Entry/128273?redirectedFrom=Normalization\#eid.

Wulster-Radcliffe, M. C., Hamernik, D. L., Reynolds, L., Lewis, G. S., \& Zinn, S. (2015). Scientific publications: From the stone tablet to the electronic tablet. Animal Frontiers, 5(3), 45-50.

Publisher's Note Springer Nature remains neutral with regard to jurisdictional claims in published maps and institutional affiliations.

Marcia D. Nichols is an Associate Professor in the Center for Learning Innovation at the University of Minnesota Rochester where she teaches literature and medical humanities. In addition to work on pedagogy, she has published on early American literature, early modern erotica, and eighteenth- and nineteenth-century medicine and midwifery. Her current book project analyzes the constructions of gender, sexuality, and masculine identity in midwifery manuals and other medical texts in the long eighteenth century.

Andrew M. Petzold is an Assistant Professor in the Center for Learning Innovation at the University of Minnesota Rochester. His current research focuses on examining how to best improve student learning and communication from within the sciences using methodology that is not common to a scientific classroom. 